\title{
Manual performance as predictor of literacy acquisition: A study from kindergarten to Grade 1
}

\author{
Anne-Lise Doyen ${ }^{\mathrm{a}, *}$, Eric Lambert ${ }^{\mathrm{b}}$, Florence Dumas ${ }^{\mathrm{c}}$, Michèle Carlier ${ }^{\mathrm{d}}$ \\ a University of Orléans, GREF, 72 rue du Faubourg de Bourgogne, 45044 Orléans cedex 1, France \\ 'University of Poitiers and CNRS, CeRCA - UMR 7295, 5 rue Théodore Lefebvre, 86073 Poitiers cedex 9, France \\ c Nìmes Université, CHROME - EA7352, rue du Docteur Georges Salan, 30021 Nimes cedex 1, France \\ dAix-Marseille Université CNRS, LPC - UMR 7290, Bât. 9, case D, 3 place Victor Hugo, 13003 Marseille cedex 3, France
}

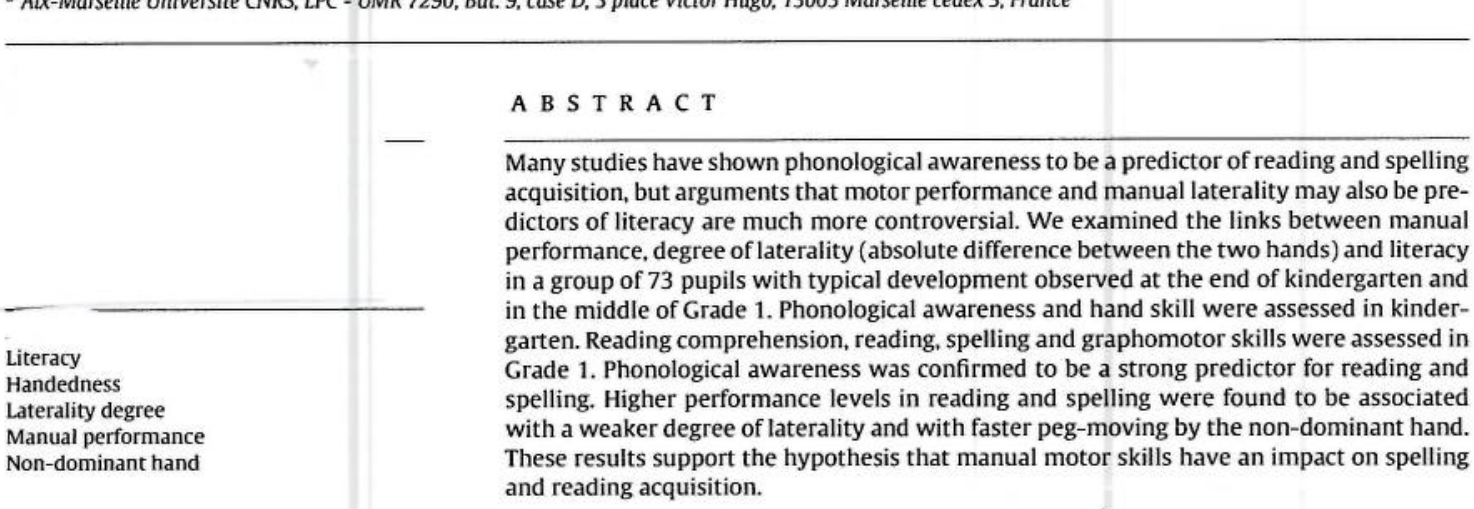

\section{Introduction}

The hypothesis that manual asymmetry and cognitive abilities are related dates back a long time in psychology. A disproportionately large number of left- or non-right handers was observed in people with an intellectual disability at the beginning of the last century (Gordon, 1921) and was later confirmed for known (e.g. Bishop, 1990a; Carlier et al., 2011) or unknown etiologies (Papadatou-Pastou \& Tomprou, 2015). The putative relationship between laterality and cognitive ability in typically developing people then stood as an interesting path to investigate. Handedness is one of the most striking forms of asymmetry and is found across the world, even though the percentage of left-handers may differ from one culture to another (Bryden, 1982; Perelle \& Ehrman, 1994; Scharoun \& Bryden, 2014). There is an ongoing debate on the cognitive advantages or disadvantages for left- or right-handedness. Many studies have focused on general cognitive ability (e.g. Nicholls, Chapman, Loetscher, \& Grimshaw, 2010; see Papadatou-Pastou \& Tomprou, 2015 for a meta-analysis), or on more specific skills such as verbal and spatial skills (Somers, Shields, Boks, Kahn, \& Sommer, 2015) but few studies have focused on reading skills (Annett \& Manning, 1990; Palmer \& Corballis, 1996).

\footnotetext{
* Corresponding author at: 72 rue du Faubourg de Bourgogne, 45044 Orléans cedex 1, France.

E-mail addresses: anne-lise.doyen@univ-orleans.fr (A.-L. Doyen), eric.lambert@univ-poitiers.fr (E. Lambert), florence.dumas@unimes.fr (F. Dumas), michele.carlier@univ-amu.fr (M. Carlier).
} 
Our study was designed to investigate the influence of two complementary aspects of motor behavior - manual performance for each of the two hands and level of between-hand asymmetry - on literacy acquisition in typically developing children, controlling for phonological skills. Previous studies have reported handedness as a discontinuous trait (left- vs. right-handers, and sometimes left-vs. mixed-handers), which has low sensitivity when screening for individual differences. For the present study, we chose to assess hand performance (hand skill), giving the possibility of using continuous traits and regardless of the direction of laterality.

The main predictor of literacy acquisition is clearly phonological awareness (i.e. the ability to perceive, identify and manipulate sounds of spoken language). The link between phonological awareness, as measured in kindergarten, and reading and spelling skills, as measured subsequently, has been recognized for a number of years now (see Melby-Lervág, Lyster, \& Hulme, 2012, for a meta-analysis), and the effect on reading has been confirmed via assessments up to the age of 14 (Roman, Kirby, Parrila, Wade-Woolley, \& Deacon, 2009). This link may be universal, as researchers have observed it in many different languages [e.g. in French (Casalis, Deacon, \& Pacton, 2011), in Dutch (de Graaff, Hasselman, Verhoeven, \& Bosman, 2011), and in non-Roman alphabet languages such as Chinese (Ziegler, Tan, Perry, \& Montant, 2000)]. Furthermore, some studies have reported the link between letter knowledge (name and sound) and reading acquisition (Leppänen, Aunola, Niemi, \& Nurmi, 2008; Shatil, Share, \& Levin, 2000), including findings for different languages, showing that letter knowledge helps children grasp the alphabetic principle (in English, McBride-Chang, 1999; in Hebrew, Levin, Shatil-Carmon, \& Asif-Rave, 2006; in French, Labat, Ecalle, \& Magnan, 2010; in Portuguese, Cardoso-Martins, Mesquita, \& Ehri, 2011).

In addition to these phonological predictors, it has been found that motor and graphomotor skills can be related to literacy acquisition, and some studies have hypothesized that there is a relation between literacy acquisition and fine motor abilities. Delayed fine motor skill acquisition was indeed found to correlate with language impairment among kindergartenage children (Adi-Japha, Strulovich-Schwarz, \& Julius, 2011). There is also a comorbidity between dyslexia and dyspraxia (Kirby \& Sugden, 2007). Haslum and Miles (2007) showed, in a sample of 12,950 10-year-old students, that $51.7 \%$ of severely dyslexic participants ( $2 \%$ of the total) presented motor difficulties. In typical children, a positive link was observed between handwriting performance and the ability to learn to read (Gentaz, Colé, \& Bara, 2003). Berninger et al. (2006) found that early training in handwriting (with orthographic and/or motor activities) improved not only handwriting skills but also word reading. Such training is more effective with handwriting than with typing, showing that practice in writing letters by hand helps children recognize them (Longcamp, Zerbato-Poudou, \& Velay, 2005). This difference between handwriting and typing may be attributable to activation of cerebral zones involved in motor activity when recognizing letters. Functional MRI scanning of four- to five-year-old children showed that after writing by hand, the "reading circuit" was activated during letter perception, but this was not the case after single-key typing or tracing (James \& Engelhardt, 2012). The authors concluded that the experience of handwriting might facilitate reading acquisition in children.

Handwriting, by definition, is a one-hand activity performed by the dominant hand (i.e. a lateralized motor experience involving the same brain lateralization as for letter recognition). Functional MRI studies have shown that the same region of the brain is activated for letter recognition and writing letters by hand: the left ventral premotor cortex for right-handed persons, and the right ventral premotor cortex for left-handed persons (Longcamp, Anton, Roth, \& Velay, 2005). The phenomenon of manual asymmetry raises the question of the different roles of the dominant and non-dominant hands in cognitive development and, in the present case, in literacy acquisition. Data on the magnitude of the difference between the two hands suggest that it may be the weakness of the non-dominant hand rather than the strength of the dominant hand that is relevant. Bishop (1984, 1990b) and Hill and Bishop (1998) focused on the role of the non-dominant hand when investigating left-handedness associated with clumsiness, finding, for example, that children with poor non-dominant hand scores made more mispronunciations in sentence repetition tasks (Bishop, 1990b). Corriveau and Goswami (2009) assessed hand dominance using a peg-moving task - the task consists of transferring 10 dowelling pegs from the furthest row of 10 holes to the nearest row of 10 holes as fast as possible. They observed that children with specific language impairment had lower performance levels with their non-dominant hand compared to age-matched children, but found no significant difference for dominant hand performance. In addition, non-dominant hand performance explained a significant part of the variance of one of the two phonological tasks (phoneme deletion, but not for reading and spelling scores). This finding supports the hypothesis of a link between the performance of the non-dominant hand and some language skills.

Annett's theory of handedness is based on asymmetry in manual activities, and one of the key assumptions was that being moderately right-handed (moderate-to-weak difference between the right hand and left hand) could maximize cognitive advantages, in particular for phonological processes (Annett, 1985; Smythe and Annett, 2006). Crow, unlike Annett, worked on the hypothesis that weakly lateralized children would be poorer readers (Crow, Crow, Done, \& Leask, 1998). The data supported the hypothesis of Crow et al., as participants with the lowest scores on the cognitive tasks recorded equal hand skills (i.e. were not lateralized). Mayringer and Wimmer (2002) failed to replicate the results of Crow's team and found no association between relative hand skill scores (left-hand minus right-hand difference) and reading and spelling; their study did not support Annett's hypothesis either. In contrast, Nettle (2003), using a multiple regression model, observed that average cognitive ability increased monotonically with increasing strength of laterality (i.e. larger difference between the right and left hand). Unfortunately Nettle (2003) did not include any data on literacy acquisition. The inconsistency between these authors' findings may be explained, at least partially, by the different cognitive and laterality tasks used and differences in the characteristics of the participants (age, sex and proportion of left-handers). Thus, the debate on the impact of the non-dominant hand and relative hand skill on literacy acquisition continues. 
There are very few studies investigating motor abilities and language development in typical populations, and even fewer that have endeavored to establish a predictive link between motor abilities and written language learning. In most studies distinguish hand dominance or the degree of laterality (see literacy acquisition (including Annett's), it was impossible to distinguish the two parameters, the absolute differaty (see Doyen \& Carlier, 2002 for a discussion of laterality indices). To thereafter - must be measured. The degree of laterality between the two hands - which we call the "degree of laterality" has been reported as a relevant parameter of laterality has not been widely used as a dependent variable, even though it Cherfouh, \& Carlier, 2008).

A review of the literature on literacy acquisition linked to motor skills shows that manual performance may bea predictor of literacy acquisition, but most of the experimental et al.'s longitudinal study (2003) covered manual performance were not designed to test long-term prediction. Dellatolas between manual motor skill and language learning, but reading, manual laterality, and cognitive tasks. They found a link and degree of laterality are not included in the experimental design.

The main goal of our study was toexaming.

in kindergarten for predicting literacy acquisition in Gration of manual performance and of degree of laterality as measured complementary predictors of literacy acquisition in Grade 1, controlling for age and phonological awareness. Putative and being that the manual performance of kinisition were assessed. The first factor is manual performance, the hypothesis Grade 1; the underlying argument is that the motor activity be linked to their reading and spelling skills, as measured in Zerbato-Poudou, \& Velay, 2005), independentlyotor activity of handwriting has an effect on letter recognition (Longcamp, manual performance and literacy a by overall hand performance (both hands). Previous studies in dominant or non-dominant hand performance, rather than a role in literacy acquisition (Bishop, 1984: Previous studies in atypical populations found the non-dominant hand to play developing children. The third hypothesis is that the difference in abilites, \& Braga, 2005), but little is known of typically is a predictor of literacy acquisition. principle.

The three hypotheses were tested in our study from kindergarten to Grade 1 Phonological and mor prodictors were measured in kindergarten, whereas literacy skills wrom kindergarten to Grade 1. Phonological and motor predictors were the influence of four potential predictors of literacy acquisition: in Grade 1 . Statistical analyses measured and dissociated non-dominant hand performance and degree of laterality.

\section{Material and method}

\subsection{Participants}

A cohort of 86 French-speaking children ( 44 girls and 42 boys) was recruited from six kindergarten classes in three public schools in the area in and around [name deleted to maintain the integrity of the review process] in France. For the follow-up (Grade 1), the cohort included 73 children ( 36 girls and 37 boys). At the start of the study, the ages ranged from 5 years 5
months to 6 years 5 months (mean months to 6 years 5 months (mean age $=6$ years 0 months). All were typically developing children following the mainstream in the classroom the day of the assessmear of kindergarten and in Grade 1. There was no selection criterion. All children pupils were excluded from the assessment were enrolled if the parents had provided prior written consent. In Grade 1, 13

they were absent the day of the second assessment.

asked to perform physical movements using the tools. handling a toy hammer and drawing with a pencil. The child was the hammer was a reliable inements using the tools. Previous data on a French cohort had shown that the hand used for left-handers for the hammer and slightly fewer forality (Doyen, Duquenne, Nuques, \& Carlier, 2001). The cohort had 10.5\% population.

\subsection{Assessments}

The authors tested and collected the data at the schools. Phonological awareness skills and manual laterality were individually assessed in June, at the end of the kindergarten school year (kindergarten sksessments). In February of year (at the beginning of the second semester of spelling and graphomotor performance were of Grade 1), reading (including reading comprehension and decoding skills), were performed using half-class groups (Grade 1 assessments).

\subsubsection{Kindergarten assessments}

Phonological awareness was tested using three phonological units: 
(1) Rhyme matching (eight items). A word is given and the child has to recognize another word with the same ending, choosing from a list of three words (e.g. word 1 is sapin (fir tree), and the possible answers are bonbon (candy), radio (radio) and marin (sailor)].

(2) Syllable segmentation (eight items). A two-syllable word is given and the child has to drop the first or last syllable, repeating only one syllable following the verbal instructions (e.g. for the word marteau (hammer), the child has to pronounce the second syllable, without saying "mar").

(3) Phoneme recognition (eight items). A list of four words is read (only three have the same initial phoneme), and the child has to recognize the one word with a different beginning [e.g. drapeau (flag), tigre (tiger), dent (tooth), doigt (finger)].

A total score for phonological awareness was calculated, with equal weight for each subtest.

Manual laterality was assessed using the peg-moving task (Annett, 1985, 2002) that had been successfully used with French populations (see Dellatolas et al., 2003; Doyen \& Carlier, 2002; Doyen et al., 2008). We followed the standard procedure (with board and pegs generously provided by Marian Annett). The participants stood facing the long side of the board and were asked to move 10 pegs as fast as they could from the back row to the front row, one by one, using only one hand for each trial. Participants chose which hand to begin with. Six trials were conducted, alternating hands for each trial. The score for a trial was the time taken to move the 10 pegs (measured in seconds). Four indices were calculated. Manual performance was the sum of the mean time of the three trials of each hand. Dominant hand was the mean of the three trials moving the 10 pegs with the faster hand (in s). Non-dominant hand was the mean of the three trials taken to move the 10 pegs with the slower hand (in s). Finally, the degree of laterality measured the absolute difference of performance between the two hands and was calculated as follows: the absolute difference between the fastest trial of the dominant hand and the fastest trial of the non-dominant hand. The goal was to assess the degree of laterality at the best performance level tested and to eliminate within-child variability.

Scores can be described as follows: the faster the participant, the lower the values for manual performance, the dominant hand and the non-dominant hand; and the less lateralized the participant, the lower the value of the degree of laterality. Reliability was estimated using Cronbach's alpha: right hand $=0.91$, left hand $=0.93$.

\subsubsection{Grade 1 assessments}

The participants were asked to perform the following six tasks:

Reading comprehension (16 items): Sentence comprehension was assessed using items taken from a standard French test (LMC-R, Khomsi, 1999). Each child read a sentence and then had to choose which one of the four pictures best depicted the situation described. Scoring was binary with one point for each picture correctly matched with the sentence. The reading comprehension score was the sum total of all correct items.

Word reading ( 24 items): Each child read aloud a list of words from a standard French test (LMC-R, Khomsi, 1999). Scoring was binary with one point for each word read correctly. The word reading score was the sum total of all correct items.

Pseudoword reading ( 12 items): Each child read aloud a list of pseudowords, such as "VOUR" or "NAJU". Scoring was binary with one point for each pseudoword read correctly. The pseudoword reading score was the sum total of all correct items.

Word spelling ( 19 items): A list of eight short noun phrases [e.g. "le petit chat" (the little cat)] was written to dictation. The word spelling score was the total number of words spelled correctly. Words appearing more than once (e.g. the definite article) were scored only once.

Pseudoword spelling ( 10 items): Children were asked to write pseudowords to dictation. The test was comprised of two 2-phoneme items (e.g./ti/), three 3-phoneme items (e.g./bry/), three 4-phoneme items (e.g./daso/) and two 5-phoneme items (e.g./mylpa/). Phono-graphemic conversion skills were assessed: two points were scored for each phoneme spelled correctly and in the right order; one point was given when the phoneme was spelled correctly but not in the right order (e.g. if the child wrote "bal" instead of "bla"). The pseudoword spelling score was the sum of all points. The split-half reliability
was 0.94 .

Symbol copying ( 35 items): The child copied a series of geometric symbols $(1 \perp \nabla \oslash \neq)$ as fast as possible within a time limit of two minutes. The symbols were printed on a sheet of paper and the child copied on paper using a pen. The test measures graphomotor skills independently of alphabetic skills. The symbol copying score is the number of symbols correctly copied.

\subsection{Statistical analysis}

In the present study, characteristics of the children were confounded with classroom characteristics, as the individuals were not randomly assigned to groups. Such multilevel data structures should be analyzed with multilevel random coefficient models (MRCM; see Kreft \& de Leeuw, 1998; Nezlek, 2008; Raudenbush \& Bryk, 2002). These techniques provide more accurate parameter estimates than do comparable estimates provided by within-person correlations or regression coefficients (see Nezlek, 2008 for a demonstration). The first step in any MRCM analysis consists of running what is called a null or totally unconditional model in which no predictors are specified at either level of analysis. Such models provide useful information about how much variation in each of the outcomes lies within and between groups. Here, the computer program HLM 6 (Raudenbush, Bryk, Cheong, Congdon, \& Du Toit, 2004) was used to test six unconditional models, one for each outcome variable. The intra-class correlation coefficients are reported in Table 1 with descriptive statistics. Chi-square tests showed 
Table 1

Estimation of unconditional model and descriptive statistics for each outcome variable.

\begin{tabular}{|c|c|c|c|c|}
\hline Outcome Variables & ICC & Chi-square & M & SD \\
\hline Reading comprehension & 0.00 & 2.51 & 7.86 & 3.51 \\
\hline Word reading & 0.01 & 6.69 & 10.96 & 5.89 \\
\hline Pseudoword reading & 0.00 & 3.34 & 6.79 & 3.26 \\
\hline Word spelling & 0.06 & 9.06 & 6.97 & 2.40 \\
\hline Pseudoword spelling & 0.02 & 6.76 & 6.21 & 2.92 \\
\hline Symbol copying & 0.18 & 19.73 & 26.21 & 8.00 \\
\hline \multicolumn{5}{|c|}{ Note: ICC: Intraclass correlation. } \\
\hline \multicolumn{5}{|c|}{$\begin{array}{l}\text { Table } 2 \\
\text { Tar }\end{array}$} \\
\hline
\end{tabular}

\begin{tabular}{|c|c|c|c|c|c|c|c|c|c|c|c|}
\hline & 1 & 2 & 3 & 4 & 5 & 6 & 7 & 8 & 9 & 10 & 11 \\
\hline 1. Phonological awareness & 1 & & & & & & & & & & \\
\hline 2. Age & -0.18 & 1 & & & & & & & & & \\
\hline 3. Manual performance & $-0.23^{\circ}$ & 0.13 & $1 \ldots$ & & & & & & & & \\
\hline 4. Dominant hand & $-0.23^{\circ}$ & 0.12 & $0.95^{\cdots}$ & 1 & & & & & & & \\
\hline 5. Non-dominant hand & $-0.22^{\circ}$ & 0.12 & $0.97^{* \cdots}$ & 0.84 & 1 & & & & & & \\
\hline 6. Degree of laterality & -0.09 & 0.01 & $0.49^{\cdots}$ & $0.24^{\circ}$ & $0.64^{\cdots}$ & 1 & & & & & \\
\hline 7. Reading comprehension & $0.61^{\cdots}$ & -0.05 & $-0.24^{\circ}$ & $-0.23^{\circ}$ & $-0.24^{*}$ & $-0.26^{*}$ & 1 & & & & \\
\hline 8. Word reading & $0.59^{\cdots *}$ & 0.14 & $-0.27^{*}$ & $-0.26^{*}$ & $-0.26^{\circ}$ & $-0.24^{*}$ & $0.83^{\cdots}$ & 1 & & & \\
\hline 9. Pseudoword reading & $0.46^{\cdots}$ & 0.10 & $-0.24^{*}$ & $-0.24^{\circ}$ & -0.23 & -0.19 & $0.76^{\cdots}$ & $0.85^{\cdots}$ & 1 & & \\
\hline 10. Word spelling & $0.56^{* *}$ & 0.16 & $-0.25^{\circ}$ & $-0.30^{* *}$ & -0.20 & -0.09 & $0.57^{\cdots}$ & $0.64 *$ & $0.67^{\cdots}$ & 1 & \\
\hline 11. Pseudoword spelling & $0.52^{\cdots}$ & -0.04 & $-0.26^{\circ}$ & -0.23 & $-0.27^{*}$ & $-0.30^{*}$ & $0.73^{\cdots}$ & $0.79^{\cdots *}$ & $0.81^{\cdots}$ & $0.52^{\cdots}$ & 1 \\
\hline 12. Symbol copying & -0.01 & 0.04 & $-0.43^{\cdots}$ & $-0.42 \cdots$ & $-0.41^{\cdots}$ & -0.21 & 0.11 & 0.16 & 0.12 & 0.08 & 0.01 \\
\hline
\end{tabular}

Note: ${ }^{p} p<0.05: * p<0.01 ; * * p<0.001$.

that the proportion of the between-class variance was never statistically significant (ns, $p s>0.11$ ), except for symbol copying $(p<0.01)$. Eighteen percent of the total variance was due to between-class differences for this last outcome, whereas no more than $6 \%$ of the total variance was explained by between-class differences for the other outcomes. In other words, classes in the present sample did not differ substantially according to achievement levels, at least in reading and spelling. Therefore, modeling variance at level 2 was not really required, and since we had only six classes, we decided to develop conditional models in which predictors were only specified at Level 1 (child-level).

We computed five separate MRCM analyses (Model 1 through Model 5) to test each motor predictor independently. The same set of MRCM analyses (Model 1 through Model 5) was repeated for each outcome variable. The first set of analyses concerned reading comprehension. The second set of analyses to the sixth set concerned word reading, pseudoword reading word spelling, pseudoword spelling and symbol copying, respectively (see Table 3). The analyses focused on child-level (within-class) relationships. The global score of phonological awareness and age were systematically entered as predictors in each conditional model and alone in the first one (Model 1). In the early stages of reading, age can explain differences in acquisition of the alphabetic principle (Bentin, Hammer, \& Cahan, 1991). In France, the difference in age within one kindergarten class is up to 11 months, which, at the age of five, means a large difference in development, particularly for motor skills. The age influence was therefore controlled for in the statistical analyses. Preliminary analyses were conducted examining phonological awareness, sex and age as predictors of reading and spelling outcomes. Sex was never significant except for pseudoword spelling $(\beta=-0.33, t=-2.04, p=0.045)$, with boys outperforming girls. However, this sex effect did not remain significant when one or the other of the motor predictors were used in the same model. We decided not to use the variable sex in the subsequent analyses.

Model 2 introduced manual performance, Model 3 the dominant hand, Model 4 the non-dominant hand and Model 5 the degree of laterality. All variables were standardized ( $\mathrm{z}$ scoring) to have $M=0, S D=1$ across the entire sample (see Raudenbush $\&$ Bryk, 2002) prior to the analysis, which is an advantage for interpretation.

\section{Results}

Mean scores (and SD) of the predictor variables in kindergarten were as follows: phonological awareness: 13.45 (4.45); manual performance: 29.91 (4.24); dominant hand: 14.11 (1.93); non-dominant hand: 15.80 (2.49); degree of laterality: $1.56(1.20)$. Mean scores in the peg-moving task were slightly lower (faster) in our sample of participants than were those Annett (1985, p. 419) obtained for six-year-old British children.

Table 2 reports the Pearson correlations. As could be expected, the three correlations between manual performance, dominant hand, and non-dominant were very high $(r s \geq 0.84)$. Correlations between each of these three variables and the degree of laterality were lower $(.49,0.24$, and 0.64 , respectively, $p s \leq 0.02)$. The degree of laterality did not correlate significantly with phonological awareness $(r=-0.09, p=0.42, n s)$, whereas the three others motor predictors did. A significant and negative correlation was obtained between phonological awareness and each of these three variables $(-0.23,-0.23$, 


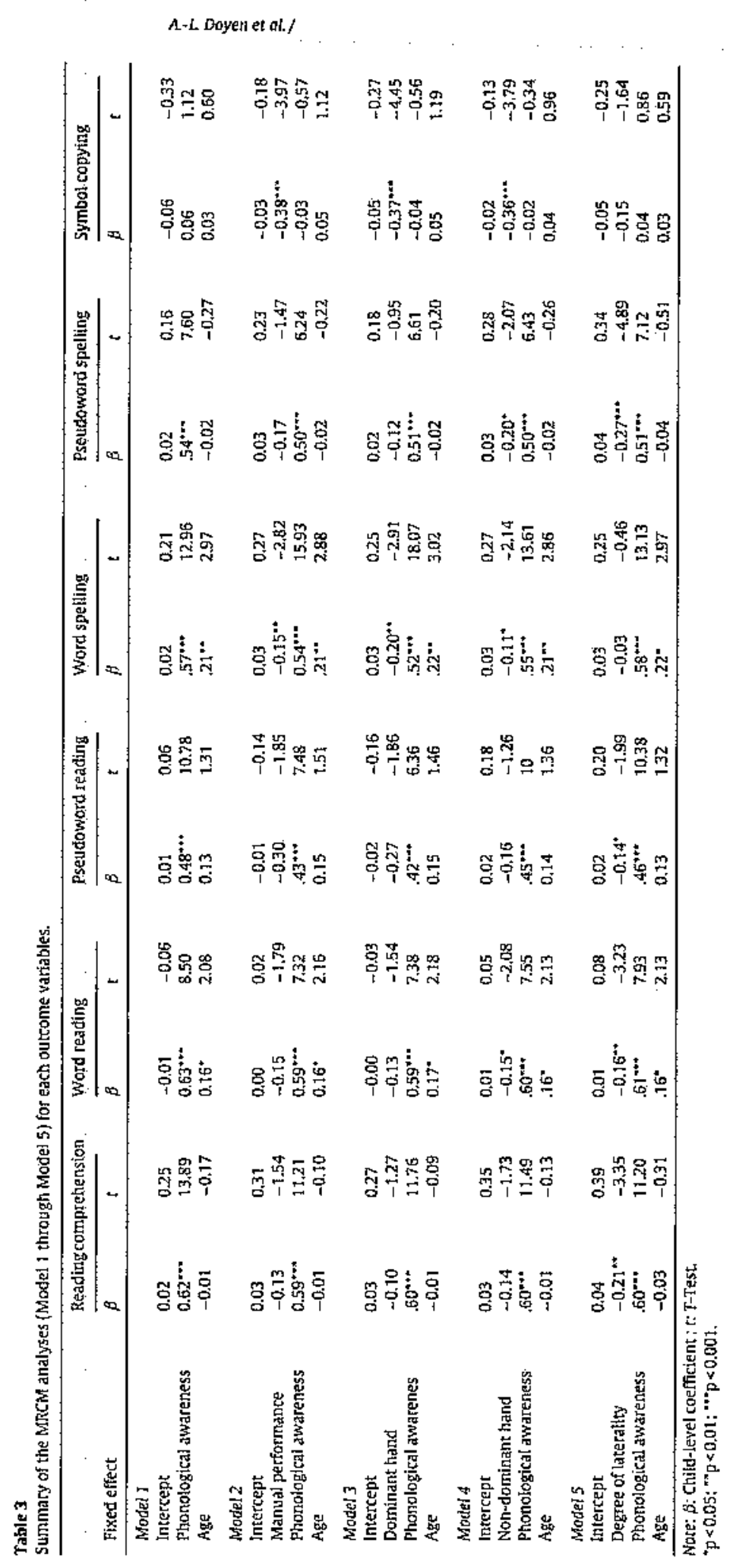


-0.22 , respectively, $p s \leq 0.05$ ). All correlations between manual predictors and literacy scores were significant and negative: the faster the fine motor skills, the higher the literacy skills. The correlation between symbol copying and phonological awareness was almost null $(\mathrm{r}=-0.01, \mathrm{p}=0.93, n s)$.

Table 3 summarizes the set of MRCM analyses (Model 1 through Model 5) that were repeated for each outcome. Model 1 is comprised of only the phonological awareness and age variables. Phonological awareness was a positive and significant predictor of all five reading and spelling variables, with a coefficient ranging from 0.48 for pseudoword reading to 0.63 for word reading. For symbol copying, neither phonological awareness nor age were significant predictors. Age was a positive and significant predictor, but only for word spelling ( $\beta=0.21$ ) and word reading $(\beta=0.16)$.

Because all variables were standardized in the same metric ( $\mathrm{z}$ scoring) before analysis, the coefficients from MRCM analyses are to be interpreted like the standardized coefficients from traditional ordinary-least-squares regression analyses.

The positive effect of phonological awareness remained strong and significant across all models with reading and spelling outcome variables (i.e. whatever motor predictor was added to the model - manual performance, dominant hand, non-dominant hand or degree of laterality). Models 2-5 show that when the motor predictors reached (or approached) significance, they were always negatively associated with reading and spelling achievement variables. Negative associations can be described as follows: the slower the participant, the longer the duration of motor task execution and the weaker the literacy scores. The effects of manual performance (Model 2) and dominant hand (Model 3) were statistically significant only for word spelling and symbol copying. The non-dominant hand (Model 4) significantly predicted four of six achievement variables (word reading, word spelling, pseudoword spelling, and symbol copying), with a coefficient ranging from -0.11 to -0.36 . Degree of laterality (Model 5) was also a good predictor for four of six achievement variables (reading comprehension, word reading. pseudoword reading and pseudoword spelling), with a coefficient ranging from -0.14 to -0.27 .

\section{Discussion}

The present study was designed to test four complementary but non-exclusive fine motor predictors of literacy acquisition in a developmental view. The study does not follow a repeated-measure longitudinal design, but rather, it documents a predictive relation between manual performance and literacy acquisition in a sample of typically developing children. The motor skills tested in kindergarten were: manual performance, dominant hand performance, non-dominant hand performance, and absolute degree of laterality. Phonological awareness was also assessed in kindergarten. Literacy was assessed in Grade 1, with reading comprehension and reading and spelling of words and pseudowords. Symbol copying was used in Grade 1 to assess graphomotor abilities implied in handwriting tasks.

As might be expected, phonological skills were the strongest predictor of reading and spelling acquisition. Our data were in line with past research studies from the 1970s that ranked phonological awareness as one of the best predictors of literacy achievement (Bus \& van IJzendoorn, 1999; Melby-Lervág et al., 2012). However, certain motor variables are also predictors of literacy acquisition, independently of phonological skills. Our study investigated motor variables that were often pooled in previous studies, testing them separately.

\subsection{Manual and dominant hand performances}

The first hypothesis was that manual performance of kindergartners could be linked to their reading and spelling skills when assessed later in Grade 1. Manual performance proved to be a significant predictor for word spelling only. The hypothesis could therefore only be partially validated: the ability of both hands did not significantly predict literacy acquisition in the next school year, except for the word spelling test, with a no significant link between manual performance and the three reading tasks. This result may seem surprising given the studies quoted above with data on embodied cognition showing that handwriting helps children memorize the shape of letters (Longcamp, Zerbato-Poudou, \& Velay, 2005) and helps with reading acquisition (James \& Engelhardt, 2012). Studies have reported that graphomotor training enhanced letter recognition and pseudoword reading (Gentaz et al., 2003; Longcamp, Zerbato-Poudou, \& Velay, 2005). It could be that a high level of manual proficiency can help a child to learn to write letters, while it is not a positive factor for reading unless there is specific training, such as haptic training (Gentaz et al., 2003), visuomotor training (Vinter \& Chartrel, 2010) or a motor strategy to distinguish between mirror letters (Dehaene, 2010).

In our study, manual performance predicted word spelling, an activity involving not only orthographical skills but also graphomotor processing, as the pupil has to write the words by hand. One difficulty here is the composite nature of the manual performance variable that is measured as the mean performance score of the two hands together. The interpretation of a link between manual performance and word spelling is reinforced by the fact that dominant hand performance presents the same profile, with the only link being with word spelling. This relation may depend on the level of graphomotor automatization (Pontart et al., 2013). The dominant hand is usually the writing hand, so with a more efficient dominant hand, graphomotor processes are easier to be automated, and more cognitive resources can be devoted to spelling processes. Evidence for this is provided by symbol copying, which was predicted by manual performance and dominant hand performance, the variable having exactly the same profile as word spelling. Symbol copying and written spelling require graphomotor abilities, and both exercises are linked to dominant hand proficiency. Spelling also requires phonological skills for orthographic representations. Word spelling can be explained by phonological awareness, which is not the case for symbol copying. Taken together, these 

observations stand as evidence for phonological skills and manual performance (in particular, dominant hand performance)
to be used as two distinct predictors for spelling achievement.

\subsection{Non-dominant hand performance}

The literature appears to have very few articles devoted to the role played by the non-dominant hand. Our study analyzed manual skills separately for each hand, and the data supported the hypothesis that non-dominant hand performance was a better motor predictor of reading and spelling skills in Grade 1 than was dominant hand performance. Dominant hand performance was significant for word spelling ability only, while non-dominant hand performance was a significant motor predictor for three literacy variables (word reading, word spelling and pseudoword spelling). The faster the non-dominant hand in kindergarten, the greater the literacy achievement in Grade 1, independently of the phonological skills. This is a key finding for understanding the link between manual motor performances and literacy acquisition. Corriveau and Goswami (2009) studied a population of children with specific language impairment and found that the non-dominant score in a pegboard task was a significant source of variation in a phoneme deletion task (but not in reading and spelling tasks). However, to the best of our knowledge, the impact of the non-dominant hand has not been investigated in a study of literacy
acquisition and motor tasks in typically developing children.

As noted above, strong laterality does not necessarily mean that the dominant hand is proficient, but rather that the nondominant hand is weaker (Annett, 1985; Annett \& Manning, 1990; Resch et al., 1997). In our study, age variability was smaller with an age range of one year. In a typical child population with small within-group variability in age, individual differences are nevertheless the rule. Differential maturational changes can be expected when comparing the motor development of the non-dominant hand and dominant hand, in particular for the less trained, non-dominant hand. Slowness or clumsiness of the non-dominant hand as a predictor of poor literacy performance is a key finding. There are now extensive reports describing dyslexic populations, observing that in addition to the phonological deficit, motor-skill deficits are more prevalent in persons with dyslexia (Kirby \& Sugden, 2007; Nicolson \& Fawcett, 2011). The causes of the associated motor deficits are still under debate. It can be hypothesized that cerebellar involvement in dyslexia affects cerebellar morphology and function (Nicolson \& Fawcett, 2011; Nicolson, Fawcett, \& Dean, 2001). The level of cerebellar symmetry has been related to the severity of the phonological decoding deficit in dyslexia (Sun, Lee, \& Kirby, 2010), but Raberger and Wimmer (2003) reported, in a population of children, that motor deficits in dyslexia related more strongly to co-morbid ADHD problems than to dyslexia itself. Rae et al. (2002) investigated cerebellar morphology and compared a group of 11 adult males with a history of dyslexia and a matched-age control group, testing pseudoword reading and Annett's peg-moving task (using an absolute non-relative degree of laterality index). A strong negative relationship was found for the entire group for the left/right grey matter volume ratio in the cerebellum and the difference in time required for peg-moving (left hand minus right hand). Greater differences between the hands were associated with a larger ratio of left-to-right grey matter in the cerebellum. Unfortunately, the authors did not present results for each hand or use absolute indices (to describe manual/cerebellar asymmetries).

Our results extend the link between non-dominant hand performance and literacy acquisition to a general child population, not just children with specific language impairment. The non-dominant hand develops more slowly (Annett, 1985) and the effect was confirmed (Bryden \& Roy, 2005; Roy, Bryden, \& Cavill, 2003). It could be hypothesized that non-dominant hand performance in young children would be a better indicator of development compared to the dominant hand (Van Mier, 2006). The slowness of the non-dominant hand could be an indicator of developmental delay, with consequences on literacy
acquisition.

\subsection{Degree of Laterality}

Our third hypothesis was that in kindergartners, the absolute degree of laterality (the absolute difference between the two hands) could be linked to their reading and spelling skills in Grade 1 . The degree of laterality proved to be a significant predictor for four out of five literacy variables (reading comprehension, word reading, pseudoword reading and pseudoword spelling). The weaker the degree of laterality in kindergarten, the better the literacy achievement in Grade 1 . The result seems counterintuitive because studies showed a link between hemispheric dominance and language acquisition (Bishop, 2013). However, it is worth mentioning that there was no direct assessment of hemispheric lateralization here. Handedness was frequently used as a proxy measure of language lateralization. Brain imaging demonstrates that handedness measures cannot be considered as a reliable indicator of cerebral lateralization for language (Groen, Whitehouse, Badcock, \& Bishop, 2013;
Mazoyer et al., 2014).

Comparing our results to the findings of Annett (2002) and Crow et al. (1998), we note that the inclusion/addition of the "right minus left percent" index to the MRCM analysis (results not presented) was much less predictive of literacy acquisition when compared to the degree of laterality (Model 5): the right minus left percent index was significantly predictive for pseudoword spelling only. This provides confirmation that the degree of laterality is a more informative variable than is the relative difference between each hand performance. In our study, the degree of laterality is the second most important factor in literacy acquisition, after phonological awareness. Furthermore degree did not correlate significantly with phonological awareness (whereas phonological awareness correlated significantly with the three other motor predictors): when phonological awareness was entered in the MRCM analysis, a significant part of variance remained explained by degree of 
laterality. Weak manual lateralization was associated with better scores for reading and spelling. Our results showed that this effect does not come from global manual performance.

Our data are in line with Annett's prediction (2002) that a weak degree of laterality could be an indicator of easier acquisition of reading and spelling processes. But neither of the two better predictors (non-dominant hand and degree of laterality) can be said to be totally independent: the weakness of the degree of laterality depended, in part, on the velocity of the non-dominant hand. Future research should investigate the separate roles of each of these two factors.

The theory of Embodied Cognition hypothesizes that all cognition, including high-level processes like language process, relies on an internal simulation of the sensory-motor experience, providing a new look at the interplay between language, motor acts and the motor system (Barsalou, 2010). Several studies have shown a close link between motor skills and cognitive by finger counocessing. For example, the SNARC effect (Spatial-Numerical Association of Response Codes) can be explained by finger counting habits during mathematical learning and then indirectly by manual abilities (Fischer \& Brugger, 2011). the degree of laterald investigate links between manual performance and literacy, and deepen the probable role played by the degree of laterality as a factor of bimanual coordination in learning and writing learning.

\section{Conclusion}

Phonological awareness in kindergarten was the strongest predictor of reading and spelling acquisition, but other predictors of motor development can be put forward, specifically the performance of the non-dominant hand and the degree of laterality. In our study, the two indices significantly predicted several aspects of literacy acquisition, as observed from one school year to the next. Our findings can suggest educational applications. The assessment of basic skills needed to acquire written language in kindergarten is very useful: particularly phonological skills for screening children at risk of language disorders. Initial language assessments in school should be combined with motor assessments to improve the diagnosis, covering manual skills and specifically the degree of laterality and non-dominant hand performance. Such motor assessments require only limited time and equipment. Future research will need to explore possible links between poor motor development and reading disabilities. Our study is limited by the relatively small sample size, even though it is in before considering the possibility of The results should be extended to other populations and using a longitudinal design before considering the possibility of training the non-dominant hand, as well as the dominant hand (Berninger et al., 2006), to facilitate literacy acquisition in young children.

\section{Acknowledgements}

We wish to thank the schoolchildren, their parents, and the teachers who agreed to take part in the study. We are very grateful to [name deleted to maintain the integrity of the review process] for her support and helpful advices during the
revision phase of the manuscript.

\section{References} Adi-Japha, E., Strulovich-Schwarz, O., \& Julius, M. (2011). Delayed motor skill acquisition in kindergarten children with language impairment. Research in
Developmental Disabilities, 32, 296-371. http://dx.doi.org/10.1016/j.ridd.2011.05.005

Annett, M., \& Manning. M. (1990). Reading and a balanced polymorphism for laterality and ability. Child Psychology \& Psychiatry \& Allied Disciplines, 31(4),

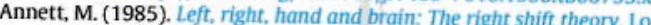

Annett, M. (2002). Handedness and brain osymmetry: The right shift London, England: Lawrence Erlbaum Associates.

Barsalou, L. W. (2010). Grounded cognition: Past, present, and future. Topics in, East Sussex, U.K: Psychology Press. http://dx.doi.org/10.1111/j.1756-8765.2010.01115.x

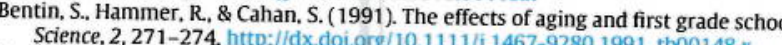

Science, 2. 271-274. hittp://dx.dol.org/10.1111/j,1467-9280.1991. tb00148.x

handwriting and composing Jum

Bishop. D. V. M. (1984). Using non-preferred hand skill to investigate pattp://dx.doi.org/10.1016/j.jsp.2005.12.003

Child Neurology, 26, 214-226. http://dx.doi.org/10.1111/1.1469-8749.1984. th04434. Bishop, D. V. M. (1990a). Handedness and develorg/10.1111/j.1469-8749.1984. tb04434.x

Bishop. D. V. M. (1990a). Handedness and developmental disorder. London, England: Mac Keith Press.

http://dx.doi.org/10.1016/0028-3932(90)90123-6 developmental language disorders. Neuropsychologia, 28, 681-690.

Bishop. D. V.M. (2013). Cerebral

http://dx.doi.org/10.1126/science.1230531

ryden, P. J., \& Roy, E. A. (2005). Unimanual perfor

http://dx.doi.org/10.1016/j.bandc.2004,08.016

Bryden, M. P. (1982). Laterality: Functional asymmetry in the intact brain. New York, U.S.A: Academic Press,

Bus, A. G., \& van IJzendoorn, M. H. (1999). Phonological awareness and early reading: a meta-analysis of experimental training studies. Journal of Educational Psychology, 91, 403-414. http://dx.doi.org/10.1037/0022-0663.91.3.403

Cardoso-Martins, C., Mesquita, T. C. L., \& Ehri, L. (2011). Letter names and phonological awareness help children to learn letter-sound relations. Journal of
Experimental Child Psychology. 109, 25-38. http://dx.doi.org/10.1016/j.jecp.2010.12.006

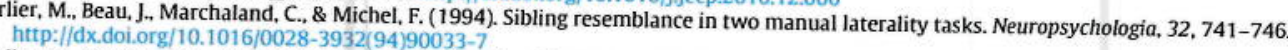

hittp://dx.doi.org/10.1016/0028-3932(94)90033-7

Carlier, M.. Desplanches, A. G., Philip. N., Stefanini. S., Vicari, S., Volterra, V., \& Swillen, A. (2011). Laterality Preference and Cognition: Cross-Syndrome
Comparison of Patients with Trisomy 21 (Down), del7q11.23 (Williams-Beuren) and del22q11. (DiGeorge or Velo-Cagio-Facal) Synt Behavior Genetics, 413-432. http://dx.doi.org/10,1007/s10519-011-9465-2 

Casalis, S., Deacon, S. H., \& Pacton, S. (2011). How specific is the connection between morphological awareness and spelling? A study of French children.
Applied Psycholinguistics, 32, 499-511. http://dx.doi.org/10.1017/S014271641100018X
Corriveau, K. H., \& Goswami, U. (2009)

Corriveau, K. H., \& Goswami, U. (2009). Rhythmic motor entrainment in children with speech and language impairments: Tapping to the beat. Cortex, 45 ,
119-130. hittp://dx.doi.org/10.1016/j.cortex.2007.09.008 Crow, T. J., Crow, L . Done D. J. \& leask, S. (1998). Relative han

Neuropsychologia, 36, 1275-1282. http://dx.doi.org/10.1016/S0028-3932(98)00039-6
De Graaff, S., Hasselman, F. Verhoeven, 1 . phoneme class. Learning and Instruction, 21, 163-173. h. (2011). Phonemic awareness in Dutch kindergartners: effects of task, phoneme position, and
Dehaene. S. (2010). Reading in the brain. New York.

Dellatolas, G. De Agostini, M., Curt, F. Kremin, H, U.S.A: Penguin Viking

performances in young children. Laterality: Asymmetries of Body, Brain, and Cognition, (2003). Manual skill, hand skill asymmetry, and cognitive

Dellatolas, G., Filho, G. N., Souza, L., Nunes, L. G., \& Braga, L W. (2005). Manual skill, hand skill asymmettry, and doi.org/10.1080/1357650 school-children with spastic cerebral palsy. Laterality: Asymmetries of Body, Brain and Cognition, 10, 161-182. http://dx.doi.org/10.1080/13576500442000012

Doyen, A.-L, \& Carlier, M. (2002). Measuring handedness: A validation study or the Bishop's card-reaching test, Lotel

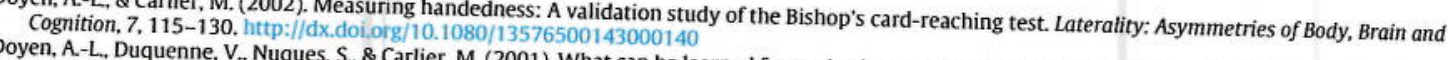

193-207. http://dx.doi.org/10.1023/A:1010205528113 What can be learned from a lattice analysis of a laterality questionnaire? Behavior Genetics, 31 ,

Doyen, A.-L, Dufour, T. Caroff, X Cherfouh, A.. \& Carlier, M. (2 family resemblance in degree of laterality. Laterality: Asymmetries of Body, Brain and Cognition, 13, 179-197.
http://dx.doi.org/10.1080/13576500701764124

Fischer, M. B Bruger. P. (2011). When

Fischer, M. H., \& Brugger, P. (2011). When digits help digits: spatial-numerical associations point to finger counting as prime example of embodied
cognition. Frontiers in Psychology, 2(260), 41-47, http://dx.doi.org/10.3389/fpsyg.2011.00260

Une étude sur la contribution du système haptique manuel. = Evaluating multisensation à la lecture pour les enfants en grande section de maternelle: A study on the contribution of the manual haptic mode. L'Année Psychologique, 103,561-584. hitory training for reading in kindergarten-age children: Gordon. H. (1921). Left-handedness and mirror writing, especially among defective children. Brain, 43, 313-368.0rg/10.3406/psy.2003.29652 http://dx.doi.org/10.1016/S0028-3932(01)00216-0

Groen, M. A. Whitehouse A. J028-3932(01)00216-0

comparison of three measures in children. PLoS One, 8, e64876. (2013). Association between handedness and cerebral lateralization for language: A

Haslum, M. N.. \& Miles, T. R. (2007). Motor performance and dyslexia in a national.org/10.1371/journal.pone.0064876

http://dx.doi.org/10.1002/dys.350

Hill, E. L. \& Bishop, D. V. M. (1998) A reath

disorder. Laterality: Asymmetries of Body, Brain and Cognition, hand preference in specific language impairment and developmental co-ordination

James, K. H., \& Engelhardt, L (2012). The effects of handwriting experience on functional brain develop 135765098397160 Neuroscience and Education, 1, 32-42. http://dx.doi.org/10,1016/j.tine.2012.08.001
Khomsi, A. (1999). LMC-R Epreuve d'évaluation de levelopment in pre-literate children. Trends in

Kirby, A., \& Sugden, D. A. (2007) Children with de la compétence en lecture = LMC-R Test for assessing reading skills. Paris: ECPA

http://dx.doi.org/10.1258/jrsm.100.4.182 developmental coordination disorders. Journal of Royal Society of Medecine, 100, $182-186$.

Kreft, I. G. G., \& de Leeuw. J. (1998). Introducing

Labat, H., Ecalle. J., \& Magnan, A. (2010). Effet d'entraînel modeling. Newbury Park, CA, U.S.A: Sage Publications.

ans. = Effect of two-mode trainings of letter knowledge: A cross-sectional study with 3- and 5-year-old children.

http://dx.doi.org/10.1016/j.psfr.2009.12.002
Leppänen, U., Aunola, K. Niemi. P. \& Nurmi Instruction, 18,548-564. http://dx.doi.org/10,1016/j.learninstruc.2007.11.004 Levin, L., Shatil-Carmon, S., \& Asif-Rave, O. (2006). Learning of letter. $2007,11.004$

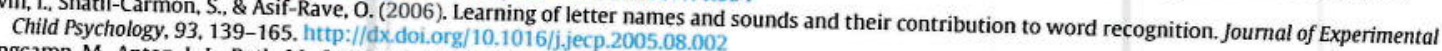
Longcamp, M., Anton, J.-L, Roth, M., \& Velay, J-L (2005), Prem-jecp.2005.08.002

write: A study on left-handers. Neuropsychologia, 43, 1801-1809. http://dx.doi.org/10,1016/j neuresented single letters depend on the hand used to

Longcamp. M., Zerbato-Poudou, M.-T., \& Velay, J.-L (2005). The influence of writing pratictice on/.neuropsychologia.2005.01.020

and typing. Acta Psychologica, 119, 67-79. http://dx.doi.org/10.1016/j.actpsy.2004,10.019

Mayringer, $\mathrm{H}_{\text {\& \& Wimmer, H. (2002). No }}$.

http://dx., \&oi.org/10.1016/S0028-3932(01)00191-9 point of hemispheric indecision. Neuropsychologia, 40, 701-704.

Mazoyer, B. Zago, Jobard, G Crivello, F, Jolio, M. Perche

lateralization for language in a large sample of healthy individuals o Tzourio-Mazoyer, N. (2014). Gaussian mixture modeling of hemispheric http://dx.doi.org/10.1371/journal.pone.0101165

McBride-Chang. C. (1999). The ABCs of the ABCs: The development of letter-name and letter-sound knowledge. Merrill-Palmer Quarterly, 45, $285-308$.
Melby-Lervalg, M. Lyster. S.-A Melby-Lervåg, M., Lyster. S.-A. H., \& Hulme, C. (2012). Phonological skills and their role in learning to read: A meta-analytic review. Psychological Bulletin,
138, 322-352. http://dx.doi.org/10.1037/a0026744
Nettle, D. (2003). Hand laterality and cognitive ability:

http://dx.doi.org/10.1016/S0278-2626(03)00187-8
multiple regression approach. Brain and Cognition, 52. 390-398.

Nezlek, J. B. (2008). An introduction to multilevel $187-8$

http://dx.doi.org/10.1111/j.1751-9004.2007.00059.x for social and personality psychology. Social and Personality Psychology Compass, 2, 842-860.

Nicholls, M. E. R., Chapman, H. L, Loetscher, T, \& Grimsh

cognitive ability. Journal of the International Neuropsychological Society. The relationship between hand preference, hand performance, and general

Nicolson, R. I., \& Fawcett, A. J. (2011). Dyslexia, dysgraphia, procedural learning and the cerel/dx.doi.org/10.1017/S1355617710000184

System and Behavior, 47, 117-127. http://dx.doi.org/10.1016/j.cortex.2009.08.016 cerebellum. Cortex: $A$ Journal Devoted to the Study of the Nervous
Nicolson, R. I., Fawcett, A. J. \& Dean. P. (2001)

http://dx.doi.org/10.1016/S0166-2236(00)01896-8
Palmer, R. E. \& Corballis. M.

http://dx.doi.org/10.1111/j.2044-8295.1996, tb02611.x

Papadatou-Pastou, M.. \& Tomprou, D.-M. (2015). In02611.x

and gifted individuals. Neuroscience \& Biobehavioral Reviews, 56, 151-165: http:-//dx.doi.org/10.1016/j.neubiorev.2015.06.017
Perelle, I. B., \& Ehrman, L. (1994). An international study of human handedness: The dally developing. http://dx.doi.org/10.1007/BF01067189

Pontart. V.. Bidet-lldei, C. Lambert, E. Morisset.

secondary grades. Frontiers in Psychology, 4, 818, http://dx.doi.org/10.3389/fpsyg. 2013.00818 handwriting skills during spelling in primary and lower 
Raberger, T., \& Wimmer, H. (2003). On the automaticity/cerebellar deficit hypothesis of dyslexia: balancing and continuous rapid naming in dyslexic and ADHD children. Neuropsychologia, 41. 1493-1497. http://dx.doi.org/10.1016/S0028-3932(03)00078-2

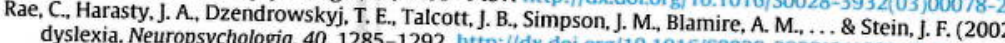
dyslexia. Neuropsychologia, 40, 1285-1292. http://dx.doi.org/10.1016/S0028-3932 (01)00216-0. (2002). Cerebellar morphology in developmental Raudenbush, S. W.., \& Bryk, A. S. (2002). Hierarchical linear models: Applications and data analysis metho

Raudenbush, S. W., Bryk, A. S., Cheong. Y. F., Congdon, R. T., \& Du Toit, M. (2004). HLM6: Lineal methods (2nd ed.). Thousand Oaks, CA, U.S.A: Sage International.

Resch, F., Haffner. J., Parzer, P., Pfueller, U., Strehlow, U \& Zerahn-Hartung C. (1997). Testing the hypothesi of the reltioncolnwood, II: Scientific Softw ability according to Annett's right-shift theory: ... \& Zerahn-Hartung. C. (1997). Testing the hypothesis of the relationships between laterality an http://dx.doi.org/10.1111/j.2044-8295.1997. th02661.x in an epidemiological sample of young adults. British Jourmal of Psychology, 88, 621-635.

Roman, A. A., Kirby, J. R., Parrila, R. K., Wade-Woolley, L 8 Dea

Grades 4, 6, and 8. Journal of Experimental Child Psychology, 102, 96-113. http://dx.doi.org/10.1016/j.jecp.2008.01.004
Roy, E. A., Bryden, P., \& Cavill, S. (2003). Hand differences in pegolved in word reading in http://dx.doi.org/10.1016/S0278-2626(03)00133-7 in pegboard performance through development. Brain and Cognition, 53, $315-317$.

Scharoun, S. M. \& Bryden, P. J. (2014). Hand preference, performance abilities, and hand selection in children. Frontiers in Psychology, 5, 82.
http://dx.doi.org/10.3389/fpsyg.2014.00082

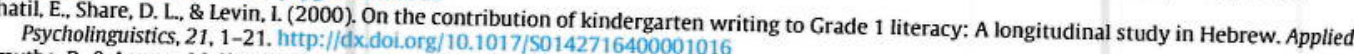

Smythe, P., \& Annett. M. (2006). Ph://dx.dol.org/10.1017/S0142716400001016

Psychiatry, 47, 205-212. http://dx.dol.org/10,1111/1469-7610.2005.01463 Predictions of the right shift theory. Jourmal of Child Psychology and

Somers, M., Shields, L. S, Boks, M. P. Kahn, R. S. \& Somi.1469-7610.2005.01463.x

Biobehavioral Reviews, 51. 48-63. http://dx.doi.org/10.1016/j.neubiorev.2015.01.003 of right-handedness: A meta-analysis. Neuroscience \&

Sun, Y.-F., Lee, J.-S., \& Kirby, R. (2010), Brain imaging findings in neubiorev.2015.01.003

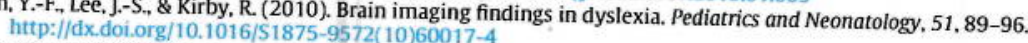

Van Mier. H. (2006).

Movement Science, 25, 657-677. http://dx.doi.org/10.1016/j.humov.2006.06.004
Mier. ${ }^{2}$. (2006). Developmental differences in drawing perfon-dominant hand in right-handed boys and girls. Human Vinter, A., \& Chartrel, E (2010). http: $: / /$ dx.doi.org/10.1016/j.learninstruc.2009.07.001
.

234-238. http://dx.doi.org/10.1111/1467-9280.00247
iegle. J. . Tan, L. H., Perry. C. \& Montant, M. (2000). Phonolters: the phonological frequency effect in written Chinese. Psychological Science, 11. 